\title{
Partial reinforcement and response reversal in rats
}

\section{J. DUTCH, Victoria University of Wellington. New Zealand}

Four groups of rats were trained to run to one end of an apparatus which consisted of a runway with a central start box and a goal box at each end. Two groups were extinguished and the other two groups were required to learn a response reversal. In the first comparison, it was found that $S$ s receiving partial reinforcement during acquisition were more resistant to extinction than Ss receiving continuous reinforcement. In the second comparison, Ss receiving partial reinforcement in acquisition learned the response reversal more rapidly than $S$ s receiving continuous reinforcement during acquisition.

Dutch (1968) compared two groups of chicks on a response reversal after 25 accuisition trials. It was found that $S$ s receiving partial reinforcement (PRF) during acquisition learned to reverse the response more rapidly than Ss receiving continuous reinforcement (CRF) during acquisition.

The following experiment was designed to extend this finding in two ways: first, by using rats as Ss, and second, by incorporating extinction groups to obtain an indication of whether or not the partial reinforcement effect could be demonstrated at this level of training.

\section{METHOD}

Subjects were 32 experimentally-naive male Sprague-Dawley rats, aged approximately 110 days. During the course of the experiment three Ss were discarded for failing to drink within 5 min during their initial trial.

The apparatus was basically the same as that described in Dutch (1968). It consisted of a single straight runway $30 \times 6 \times 8$ in., with an $8 \times 8$-in. goal box at each end. Each goal box was equipped with a perspex guillotine door. Two additional guillotine doors were used to divide off the middle 6 in. of the runway so that it served as a start box. The Ss were placed in to the start box through a trap door in the roof of the runway in a uniform manner. The runway was made of metal painted flat gray throughout, and had a perspex roof. The water holder was made out of wood painted flat gray and was suspended from the end wall of the goal box at a height which prevented $S$ from seeing whether it was loaded until he was directly above it. The reward was $80 \mathrm{mg}$ of water.

Three weeks before the commencement of the experiment Ss were placed on a water deprivation schedule permitting 15 min access to water each $24 \mathrm{~h}$. Food was ad lib.

In the acquisition phase of the experiment one arm of the runway was blocked off by covering the appropriate start box door. In this way the acquisition phase consisted of forced trials. During acquisition half the Ss in each group were forced to run to the left goal box, the other half were forced to run to the right goal box.

Each $S$ was given 25 acquisition trials over three days to the appropriate goal box. Reversal and extinction trials were begun on the fourth day, and continued at 10 trials per day until the appropriate criterion was reached.

On Day 1 of acquisition, all Ss received one rewarded goal box placement followed by five spaced rewarded trials.

On Days 2 and 3 of acquisition, Groups $100 \mathrm{E}(\mathrm{N}=6)$ and 100R $(\mathrm{N}=8)$ received 10 spaced rewarded trials each day, and Groups $50 \mathrm{E}(\mathrm{N}=6)$ and $50 \mathrm{R}(\mathrm{N}=9)$ received 10 spaced trials each day rewarded on a 50\% FR schedule. All trials were spaced at approximately 8 -min intervals. On all trials Ss were confined in the goal box for $5 \mathrm{sec}$ before being returned to their home cage.

On Day 4 extinction was commenced for Groups 100E and $50 \mathrm{E}$, and reversal was commenced for Groups 100R and 50R.
All Ss were given 10 trials per day until they reached their appropriate criterion.

The procedure for extinction was the same as for acquisition except that water was never present in the holder. The criterion for extinction was a failure to enter the goal box within $2 \mathrm{~min}$ on a total of three trials, not necessarily consecutive.

The procedure for reversal was as follows. $S$ was placed in the central start box, both doors were opened simultancously and left open so that $S$ could retrace until he entered either goal box. That goal box door was then lowered and $S$ was kept there for $5 \mathrm{sec}$. Both goal boxes were equipped with water holders, but no entry into the goal box that $S$ had been forced to run to in acquisition was rewarded. The criterion for reversal was nine correct trials in any set of 10 trials.

\section{RESULTS AND DISCUSSION}

In reversal learning, the mean number of trials to criterion was 16.8 for Group 100R and 12.8 for Group 50R. Using the Mann-Whitney test (Siegel, 1956) $U=14.5(p<.05)$.

In extinction, the mean number of trials to criterion was 10.2 for Group 100E, and 17.0 for Group 50E. Using the Mann-Whitney test, $U=6(p=.032)$.

On the basis of these results it appears that Ss receiving PRF in acquisition are more resistant to extinction than $S$ s receiving $C R F$ in acquisition, and that $S$ s receiving PRF in accuisition learn a response reversal more rapidly than Ss receiving CRF during acculisition.

Dutch (1968) suggested that the linding of more rapid reversal learning in PRF Ss might be described in terms of either Theios \& Blosser's (1965) overlearning reversal effect, or Amsel's (1962) frustration hypothesis, or in terms of the shift in probability of reward. The results of the present experiment suggest that the overlearning reversal effect does not apply here. If PRF Ss had overleamed then they should also extinguish more rapidly on the basis of findings from Capaldi (1958). The hypothesis derived from Amsel (1962) also appears to be inadequate as it was assumed that faster reversal learning for PRF Ss was the result of fractional anticipatory frustration $\left(\mathrm{r}_{\mathrm{F}}\right)$ being evoked by the limited number of nonreinforced trials without the stimulus component $\left(\mathrm{s}_{\mathrm{F}}\right)$ signalling approach. This, however, should also result in PRF Ss reaching the extinction criterion more rapidly than ( RF Ss because the CRF Ss would need several nonrewarded trials before $r_{F}$ developed and began to compete with fractional anticipatory reward $\left(r_{R}-s_{R}\right)$.

A third explanation depends on a shift in reward probability for PRF Ss from $50 \%$ to a possible $100 \%$ which could possibly account for PRF Ss persisting in the new response to a greater extent than CRF Ss. If, however, the result of extinction is attributed to the partial reinforcement effect, it is difficult to account for the variation in response shown by PRF Ss, particularly as it was found that seven out of nine $S$ s in Group 50R made the correct choice on the first reversal trial. whereas only three out of eight Ss in Group 100R made a correct first choice.

This result also bears on the issues raised by Spear \& Pavlik (1966) and suggests that further research should incorporate some manipulation of magnitude of reward.

\section{REFERENCES}

AMSEL, A. Frustrative nonreward in partial reinforcement and discrimination learning. Psychological Review, 1962.69, 306-328. 


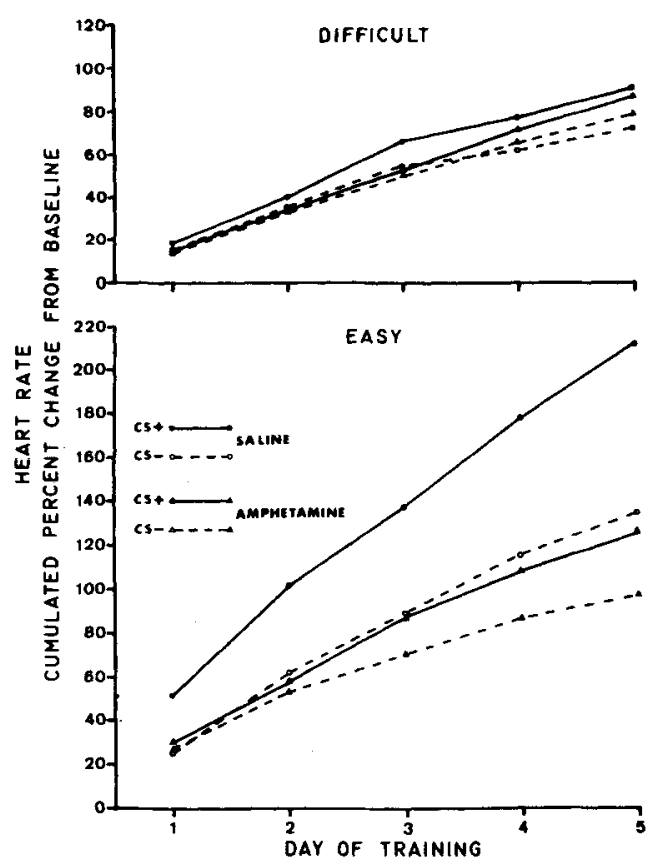

Fig. 2. Mean HR responses to CS+ and CS- for the average $S$ in each group cumulated over days of training. Per cent changes represent HR decelerations.

The HR discrimination portrayed in Fig. 2 shows the debilitating effect of amphetamine on both the easy $(p<.048)$ and the difficult $(p<.048)$ tasks. In addition, the effects of task difficulty were also significant for the amphetamine group $(p<.048)$ and the saline controls $(p<.028)$.

\section{DISCUSSION}

Responding

The effects of amphetamine are apparently very complex ranging from facilitation to debilitation depending on the response system and the task involved. Physiologically, the direct action of d-amphetamine is on the sympathetic portion of the autonomic nervous system and not on the skeletal motor system. Increased motor activity as a result of amphetamine administration is an indirect manifestation of the drug's direct effects on the cortex and the reticular activating system (Goodman \& Gilman, 1966). Total NM CRs were not affected although spontaneous and random responses may have been.

The HR-CR, however, is the consequence of both sympathetic and parasympathetic impulses and is a phasic deceleration in the rabbit. Increased sympathetic activation by amphetamine via the cardiac acceleratory nerve would increase HR and thus partially suppress deceleratory HR CRs, as the results have indicated.
A significant decrease in HR responding was also demonstrated as a result of task difficulty. The tendency for the HR-CRs to decrease in amplitude as a discrimination task becomes more difficult has been previously noted by the authors in other studies and is presently under investigation.

The debilitating effect of amphetamine on overall HR responding was significant for the "easy" task but not for the difficult group. Presumably with the already low responding in the "difficult" group there was less opportunity for the amphetamine to evidence a debilitating effect.

\section{Discrimination}

The discrimination results portrayed in Figs. 1 and 2 clearly confirm the difference in task difficulty for both the NM and the HR discriminations. Amphetamine, however, affected the two response systems in opposite directions. The facilitation of the NM discrimination on the "difficult" task without increasing overall NM responding lends support to Cole's (1967) cue-monitoring or alertness concept of amphetamine, whereby increased activation of some CNS area results in greater attention and hence a better discrimination. It seems reasonable that differential effects of amphetamine on NM discrimination are due to the opportunity to evidence a facilitation on the "difficult" task which was virtually insoluble by the saline control group, and to evidence no effect on the "easy" task in which the saline control group was able to achieve a good discrimination.

The debilitating effect of amphetamine on HR discrimination for both tasks is somewhat puzzling; and is apparently a result of the direct sympathetic action of amphetamine on HR responding coupled with its effect on some CNS area affecting the translation of the discrimination to the HR response system. In addition, heart arrhythmias, known to occur as a result of amphetamine administration (Goodman \& Gilman, 1966) were more likely responsible for the decreased differential HR responding.

\section{REFERENCES}

COLE, S. O. Experimental effects on amphetamine: A review. Psychological Bulletin, 1967,68, 81-90.

GOODMAN, L. S., \& GILMAN, A. The pharmacological basis of therapeutics. New York: MacMillan, 1966. P. 500.

haUTY, G. T., PAYNe, R. B., \& BAUER, R. O. Physiological costs incurred by dextro-amphetamine. Journal of Comparative \& Phy siological Psychology, 1957, 50, 647-651.

PAYNE, R. B., HAUTY, G. T., \& MOORE, E. W. Restoration of tracking proficiency as a function of amount and delay of analeptic medication. Journal of Comparative \& Physiological Psychology, $1957,50,146-149$.

YEHLE, A. L. A method for transducing nictitating membrane and breathing rate responses in the rabbit. Journal of the Experimental Analysis of Behavior, 1968, 11, 207-208. NOTE

1. The authors wish to express their thanks to J. L. Yehle for his invaluable assistance in the construction of the electronic programming equipment.
CAPALDI, E. J. The effect of different amounts of training in the resistance to extinction of different patterns of partially reinforced responses. Journal of Comparative \& Physiological Psychology, 1958, $51,367-371$.

DUTCH, J. Partial reinforcement and response reversal in chicks. Psychological Reports, 1968, 22, 272-274.
SPEAR, N. E., \& PAVLIK, W. B. Percentage of reinforcement and reward magnitude effects in a $T$ maze: Between and within subjects. Journal of Experimental Psychology, 1966, 71, 521-528.

THEIOS, J., \& BLOSSER, D. Overlearning reversal effect and magnitude of reward. Journal of Comparative \& Physiological Psychology, 1965, $59,252-257$. 